\title{
REVISTAMARACANAN
}

Nota de Pesquisa

\section{Crise: entre o comum, o sentido, o governo, o motim e a comuna}

\author{
Crises: between the common, the sens, the government, the riot and the \\ commune
}

\author{
Frederico Lyra de Carvalho \\ Université Lille 3 - Sciences Humaines et Sociales \\ lyrafred@gmail.com
}

\begin{abstract}
Resumo: $O$ presente artigo se propõe a discutir quatro autores diferentes que, em três obras distintas e desde diferentes pontos de vista, discutem a crise presente: Myriam Revault d'Allonnes (La crise sans fin); Pierre Dardot e Christian Laval (Ce cauchemar qui n'en finit pas) e Joshua Clover (Riot, strike, riot). Através do prisma da crise, esta articulação será feita com a mobilização do conceito de comum, observando a metamorfose de sentido do termo de crise, da mudança no paradigma do governo e nas formas políticas dos motins e das comunas. O artigo tem como objetivo demonstrar que, embora cada um desses autores faça uma contribuição importante para o debate em torno da compreensão da crise, eles se tornam mais efetivos se olhados juntos. Neste intuito, para organizar essa articulação, além dos autores citados, faremos recurso aos autores Anselm Jappe e Paulo Arantes.
\end{abstract}

Palavras-chave: Crise; Comum; Governo; Motim; Comuna.

Abstract: The present article proposes to discuss four different authors who, in three different works and under different points of view, discuss the present crisis: Myriam Revault d'Allonnes (La crise sans fin); Pierre Dardot e Christian Laval (Ce cauchemar qui n'en finit pas) e Joshua Clover (Riot, strike, riot). Through the prism of the crisis, this articulation will be made with the mobilization of the concept of common, observing the methamorphosis of the meaning of the term of crisis, the change in the paradigm of government and in the political forms of riots and communes. The article aims to demonstrate that while each of these authors makes an important contribution to the debate around understanding the crisis, they become more effective if viewed together. In order to organize this articulation, besides the mentioned authors, we will make resources to the authors Anselm Jappe and Paulo Arantes.

Keywords: Crisis; Commun; Government; Riot; Commune.

Recebido: Novembro 2017

Aprovado: Dezembro 2017 


\section{Introdução}

Não deixa de ser no mínimo curioso que o filósofo Pierre Dardot e o sociólogo Christian Laval, no prefácio do seu quinto livro escrito em parceria, à saber, Ce cauchemar qui n'en finit pas, lançado em 2016, observem que "a lógica minoritária do comum ainda não encontrou a sua expressão de massa, os seus quadros institucionais, a sua gramática política. Nós estamos apenas no esboço de uma nova configuração revolucionária. E esse atraso nos inquieta". ${ }^{1}$ Os autores acreditavam que a crise de 2008 poderia desencadear um novo movimento revolucionário de escala europeia, ou até mesmo planetária. Isso é evidenciado no livro anterior da parceria, publicado no ano de 2014, onde Dartot e Laval apostam alto que o que eles e outros autores denominam por "comum", ou mais precisamente como o "princípio do comum", ${ }^{2}$ iria se generalizar e se tornar quem sabe uma palavra de ordem e princípio organizacional para uma nova esquerda que, de certa forma, já estaria lá em processo de maturação pronta para se insurgir e tomar corpo com a oportunidade aberta pela crise. Segundo os autores, a partir deste princípio "o que importa, é menos de reabilitar a experiência em comum que de dar todo o espaço à experiência do comum, quer dizer à experiência de uma coparticipação nos assuntos públicos. O que está em jogo é a diferença entre $o$ que é comum e $o$ comum". ${ }^{3}$ Este princípio do comum estaria acumulando uma forte carga de expectativa e a aposta dos autores, como a primeira citação acima e o subtítulo do livro (ensaio sobre a revolução no século XXI) não parecem deixar dúvidas, era a de que em torno do comum uma nova configuração revolucionária enfim poderia tomar forma, "a revolução é desta forma o momento de aceleração, de intensificação e de coletivização desta atividade consciente que nós designamos sob o nome de "práxis instituinte", ${ }^{4}$ o momento de auto instituição de uma sociedade. É pela atividade prática que pode-se concretizar a possibilidade de um novo sujeito coletivo emergir. É a atividade prática que transforma as coisa em comum, "o comum não é um bem". ${ }^{5}$ Seria através do princípio do comum que esta práxis instituinte tomaria corpo. Além disto, Dardot e Laval tomam a precaução de não substantivar o comum para não dar margens para que outros se autorizem a submeter o comum à sua própria vontade e desta forma tratá-los como se fossem objetos de sua posse. Não são bens que possam vir a ser privados, mas "o princípio político a partir do qual nós

\footnotetext{
${ }^{1}$ DARDOT, Pierre; LAVAL, Christian. Ce cauchemar qui n'en finit pas: Comment le néolibéralisme défait la démocratie. Paris: La Découverte, 2016, p. 15. Todas as traduções são de responsabilidade do autor.

2 DARTOT, Pierre; LAVAL, Christian. Commun: Essai sur la révolution au XXI siècle. Paris: La Découverte/Poche, 2015, p. 49. A primeira edição desta obra é de 2014, a que foi consultada é a versão de bolso (poche).

${ }^{3}$ DARDOT, Pierre; LAVAL, Christian. Ce cauchemar qui... Op. cit., p. 226. Grifo dos autores.

${ }^{4}$ DARTOT, Pierre; LAVAL, Christian. Commun... Op. cit., p. 575.

${ }^{5}$ Ibidem, p. 49. Grifo dos autores.
} 
devemos construir os comuns e nos reportar a eles para Ihes preservar, Ihes expandir e Ihes fazer viver". ${ }^{6}$

Apenas dois anos depois de formular este princípio os autores já se mostram cépticos com a possibilidade da própria ideia tomar forma e, sobretudo, com o tempo que este princípio do comum está levando para se manifestar como experiência política concreta e assim ser capaz de se colocar como eixo organizacional dando forma a uma nova correlação de forças com a lógica dominante. Logo nas primeiras linhas da obra de 2016 os autores confessam que "nós escrevemos este livro com um sentimento de urgência. A corrida está empenhada". ${ }^{7}$ Essa inquietude parece tomar forma em uma temporalidade de urgência, ${ }^{8}$ como os autores mesmo observam. Se por um lado é verdade que os autores estão longe de descartar completamente a ideia do comum, ${ }^{9}$ por outro lado, sob a égide deste tempo de urgência, dois anos não parece mais ser um tempo aceitável para que um princípio político tome uma forma concreta e saia do seu esboço. No entanto, talvez mais do que inaceitável, dois anos, face à "aceleração decisiva dos processos econômicos e securitários que transformam em profundidade nossas sociedades assim como as relações políticas entre governados e governantes ${ }^{\prime 10}$ ou seja, face à crise na qual o sistema capitalista se encontra, passa a ser um tempo que impõe uma espera com o qual Dardot e Laval não parecem mais contar. ${ }^{11}$

\section{A crise como metáfora e como um novo ponto de partida}

A filósofa Myriam Revault d'Allonnes observa que de certa forma o "nosso presente é invadido pela crise". ${ }^{12} \mathrm{O}$ presente coincidiria com a crise, seria a própria crise e este seria, segundo a autora, um fato quase que incontestável. A autora afirma que na crise atual "o presente se torna a única dimensão temporal disponível para a ação". ${ }^{13}$ É interessante observar que aqui a crise aparece no singular mesmo sendo uma crise capaz de totalizar os mais diferentes registros e dimensões possíveis como: a economia, as finanças, a política, a cultura, os valores, a autoridade, a educação, a juventude ou a família, como insiste a

\footnotetext{
${ }^{6}$ DARTOT, Pierre; LAVAL, Christian. Commun... Op. cit., p. 49.

7 DARDOT, Pierre; LAVAL, Christian. Ce cauchemar qui... Op. cit., p. 7.

${ }^{8}$ Ou como diria o filósofo Paulo Arantes caracterizando o novo tempo do nundo por ele teorizado como o: "tempo intemporal da urgência perpétua", cf.: ARANTES, Paulo. O novo tempo do mundo. In O Novo Tempo do Mundo: e outros estudos sobre a era da emergência. São Paulo: Boitempo, 2014, p. 94.

${ }^{9} \mathrm{O}$ capítulo que conclui o livro de 2016 tem como título: "La démocratie comme expérimentation du commum" (A democracia como experimentação do comum).

10 DARDOT, Pierre; LAVAL, Christian. Ce cauchemar qui... Op. cit., p. 7. Grifo dos autores.

${ }^{11} \mathrm{~A}$ articulação entre o novo tempo do mundo e as modalidades de espera induzidas por este tempo é o objeto central de um outro ensaio de Paulo Arantes intitulado "Zonas de Espera" e encontrado no mesmo volume anteriormente citado. Esta espera, segundo o autor, é experimentada nas mais diversas zonas que vão de campos de refugiados, passando pelas prisões modelos, salas de aeroporto ou festas raves. Dentre outros aspectos este tempo de espera é punitivo e, mais importante para o nosso caso, imobilizador. Cf.: ARANTES, Paulo. Zonas de Espera. In: O Novo Tempo do Mundo: e outros estudos sobre a era da emergência. São Paulo: Boitempo, 2014, p. 141-198.

12 D'ALLONNES, Myriam Revault. La crise sans fin: essai sur l'expérience moderne du temps. Paris: Seuil, 2012 , p. 9.

${ }^{13}$ Ibidem, p. 114.
} 
autora. ${ }^{14}$ Segundo d'Allonnes, todas estas diferentes esferas da existência estariam em crise. Desta forma, retomando os termos de Marcel Mauss ela fala da crise como um "fato social total". Ela é, de certa forma, totalizante. Não sem evidenciar o espanto que um único termo como o de crise possa englobar a heterogeneidade da atualidade de todas estas experiências, d'Allonnes nos diz que na atualidade crise é "ao mesmo tempo o meio e a norma da nossa existência". Além disso, se na sua origem o termo grego de krisis (de onde deriva o termo de crise) carregava consigo a necessidade de uma decisão à ser tomada ou indicava um momento decisivo de um processo em curso, na situação presente o termo de crise parece indicar o inverso, à saber, "a crise aparece hoje em dia marcada pelo carimbo da indecisão talvez do indecidível". Este efeito de suspensão seria o paradigma da crise presente. Desta forma, estreitamente ligada à nossa relação e experiência do tempo a "crise se tornou permanente". ${ }^{15}$ Permanente de tal forma que coloca em cheque o conceito tradicional mesmo de crise onde essa permanência não deveria existir:

Os momentos de crise são constantemente percebidos como inelutáveis senão como previsíveis mas nós vislumbramos - de uma maneira ou de outra - a sua saída, sua resolução. A crise é movimento e ela está no movimento: ela é o que deve-se atravessar, o que nossa existência não pode deixar de atravessar, que nos atravessa mas ela não é nem contínua nem permanente. Ela nos permite pensar a articulação do contínuo e do descontínuo. ${ }^{16}$

D'Allonnes concentra a sua análise na tentativa de desmembrar o momento atual destas múltiplas crises que seria, sob seus olhos, um esgotamento do projeto moderno e que ao final de contas estaríamos vivendo em um limiar histórico que, sob o ponto de vista da autora, ainda não seria plenamente discernível. D'Allonnes sustenta três teses centrais na sua obra, primeiramente, como visto acima, o termo de crise perdeu o seu sentido original e isto demanda uma reflexão conceitual. De certa maneira a autora observa que a crise perde o seu sentido na dupla acepção do termo: não teria mais o mesmo significado nem uma direção propriamente dita. Em seguida, esta crise deve ser percebida de uma nova maneira, ela possuiria uma natureza distinta de crises anteriores. Desta forma "a crise não é tanto o que convém de "ultrapassar" mais de onde se deve partir ou repartir para pensar o nosso presente". ${ }^{17}$ Por fim, dada a situação atual, crise não deve mais ser entendida como um conceito, mas como uma metáfora de algo que é vivido e que não saberíamos descrever conceitualmente.

Para sustentar esta concepção de crise como ponto de partida, a filósofa se apoia em uma parábola que ela encontra em Hannah Arendt na qual esta última explicita a ideia de "brecha no tempo" como uma ideia que reenvia um tempo que seria privado de tradição, um

\footnotetext{
${ }^{14}$ D'ALLONNES, Myriam Revault. La crise sans fin... Op. cit., p. 7. Os exemplos são da própria autora.

${ }_{15}$ Ibidem, p. 10. Por outra via, comentando sobre este mesmo aspecto de crise permanente, o filósofo Anselm Jappe tenta dar um formato mais geral e preciso a esta mesma constatação: "este sistema [capitalista] torna impossível toda gestão consciente da sociedade, ele conhece igualmente uma situação de crise permanente", In: FRIOT, Bernard; JAPPE, Anselm. Après l'économie de marché: une controverse. Paris: Atelier de création libertaire, 2014, p. 26.

${ }^{16}$ Ibidem, p. 112.

${ }^{17}$ Ibidem, p. 13.
} 
local de pensamento e ação, um tempo que é "rompido ao meio, no ponto onde o homem se sustenta e que é uma "brecha no tempo". ${ }^{18}$ Essa brecha no tempo é interpretada por d'Allonnes como sendo uma brecha política. A busca por uma brecha política viria para suprir ao mesmo tempo a ausência de sentido e a ausência de saída na qual Arendt se encontrava em meados dos anos 50 face aos ditos regimes totalitários e face à bomba atômica. Tentando dar uma atualidade nova a esta ideia d'Allonnes propõe que perante a falta de orientação possível em qualquer tradição (e ela não deixa dúvidas de que é na tradição ocidental que ela está pensando $)^{19}$ e sob o risco de ver o mundo condenado, nos seus termos, à usura e à entropia, devemos entender esta realidade que nos está posta pois "não temos outra chance que não a de tomar uma nova partida". Para autora, toda ação, e especialmente as ações políticas, deveriam neste momento buscar provocar um novo começo. Neste esforço de renovação "é da força do presente que vem a força para reconfigurar o tempo". ${ }^{20}$ Desta forma a crise poderia vir a ser um novo ponto de partida para um futuro ainda incerto. Não sem um certo esforço ela busca dar uma face positiva para esta crise, como se esta, no final das contas, pudesse vir a ser uma oportunidade para se reinventar uma certa forma política. Política ela mesma em crise. Nesta reversão a incerteza frente ao futuro seria a condição mesma para uma nova prática democrática. Desta forma um certo "desencanto" com práticas mais correntes nas democracias ocidentais ou mesmo o fim da figura heróica na política longe de ser um sinal de esgotamento, deve ser vista na realidade como um deslocamento para uma outra esfera pública. Esfera esta que, segundo a autora, se manifesta na proliferação de novas práticas como a de fóruns cidadãos, petições, novos coletivos de contestação e experiências de resistência. ${ }^{21}$ Se por uma lado ela não aprofunda o que seriam exatamente nem estes novos coletivos de contestação nem estas experiências de resistência, ela não deixa de observar que "a sociedade democrática é a condição - e não apenas a ocasião - das suas emergências e das suas instituições" e que, além disso, essas novas formas políticas "não visam nem "fazer a revolução" nem "tomar o poder". ${ }^{22}$ Desta maneira, boa parte das reações e hesitações das pessoas quando têm de se confrontar com esta crise totalizante não passaria, afinal de contas, de mero preconceito quando defrontadas a algo de novo. "A crise, nos diz a autora, não constitui uma catástrofe se nós respondemos a ela com ideias todas feitas, dito de outra forma pela reiteração de preconceitos que se tornaram inadequados". ${ }^{23}$

Além disso, segundo d'Allonnes, a crise deve ser vista como uma metáfora de outra coisa. Isto se deve sobretudo pela impossibilidade dela ser conhecida em sua totalidade. Ela é de certa forma totalizante, mas esta totalidade ultrapassa, por assim dizer, a compreensão conceitual. Como foi dito acima, a autora observa que a crise atravessa os mais diversos

\footnotetext{
${ }^{18}$ Cf. : ARENDT, Hannah. Entre o Passado e o Futuro. São Paulo: Perspectiva, 2014; D'ALLONNES, Myriam Revault. La crise sans fin... Op. cit., p. 167.

${ }^{19}$ Entre outras afirmações ela observa que "a confusão e a falta de orientação atingem a duração da vida das sociedades ocidentais". Ibidem, p. 150.

${ }^{20}$ Ibidem, p. 169, 170.

${ }^{21}$ Voltaremos a este ponto mais adiante especialmente através de uma feliz observação de Anselm Jappe, além de outra de Pierre Dardot e Christian Laval.

22 ARENDT, Hannah. Entre o Passado... Op. cit., p. 143-144.

23 Ibidem, p. 163.
} 
campos da existência humana o que dificultaria ou mesmo impediria que ela seja aceita e pensada conceitualmente - mas não impediria de forma alguma que façamos uma ideia do porquê de se insistir com o termo crise. Tendo Hans Blumenberg como ponto de apoio, a autora observa que a metáfora da vida como sendo a travessia de uma navegação no mar pode servir como analogia para a compreensão a mudança do paradigma da crise. Esta metáfora também deve ser compreendida de uma nova forma pois, se antes ela articulava uma dialética entre um porto seguro (a terra firme) e o alto mar, no tempo presente ela demanda uma nova variação: "na falta de poder trazer o barco a um porto seco para repará-lo, nós devemos fazê-lo em pleno mar. $E$ ainda mais, na ausência de uma terra firma que possamos atingir, o barco já deve ser construído em pleno mar". ${ }^{24} \mathrm{Na}$ impossibilidade de se totalizar a experiência da crise a opção que teria sobrado é a de metaforizá-la, desta forma a autora sustenta que "a crise talvez seja uma metáfora absoluta da época contemporânea". ${ }^{25}$

No entanto, nunca é demais insistir que é bem das sociedades e democracias ocidentais que a autora está falando. Nas poucas vezes que o sistema capitalista dá as caras no texto, é sob esse ponto de vista que ele aparece. É bastante possível que quando a autora insiste em um recomeço em outra partida como a última chance política sejam estas democracias ocidentais que a autora tenha em mente. Não é por acaso que ela conclui o livro dizendo que restaram apenas duas orientações possíveis para o presente: ou "nos instalamos na jaula ou na brecha". ${ }^{26}$ Ou a jaula de aço de Max Weber ou a brecha de Hannah Arendt. Não deixa de ser curioso que d'Allones conclua com uma bifurcação destas: ou continuamos como estamos ou tentamos mudar timidamente a situação presente, mas sem maiores ambições por uma tomada do poder e muito menos ambições revolucionárias.

\section{Crise como modo de governo}

Pierre Dartot e Christian Laval concordam com as observações de Myriam Revault d'Allonnes relativas à inversão de sentido do termo de crise. Eles dão razão à autora quando ela observa que este último, ao invés de nominar um momento de decisão, passa a significar um estado permanente. No entanto, apesar de todo o esforço em direção a uma justificativa de um sentido metafórico do termo de crise, para ambos os autores d'Allonnes não vai muito além de generalidades conceituais. De certa forma, por ser vista como metáfora e possibilidade de ponto de partida para outra coisa que no fundo não parece vislumbrar algo muito além da situação presente, mas algo como uma democracia ocidental atualizada, a crise que é discutida por d'Allonnes carece de conteúdo. Eles remarcam que se por um lado é verdade que o sistema está em uma crise crônica e totalizante, "ela não poupa nenhum aspecto da realidade, pois a razão neoliberal não poupa nenhuma dimensão da realidade", por

\footnotetext{
${ }^{24}$ D'ALLONNES, Myriam Revault. La crise sans fin... Op. cit., p. 186. Grifo da autora.

${ }^{25}$ Ibidem, p. 196.

${ }^{26}$ Ibidem, p. 197.
} 
outro lado, isso "significa também que o sistema se alimenta da crise, que ele se reforça pela crise". ${ }^{27}$ A crise para Dardot e Laval não pode ser vista como sendo apenas uma metáfora nem tão pouco como um novo ponto de partida, para estes autores a crise atual seria no fundo um modo de governo. ${ }^{28}$

"A crise alimenta a crise em uma espiral sem fim", ${ }^{29}$ é essa situação entrópica que é caracterizada pelo autores. Eles também observam que desta vez mesmo os países centrais não conseguem mais escapar desta lógica e que a precarização e crescimento da desigualdade social está se acelerando em grande velocidade, e assim bloqueando qualquer saída por meios mais tradicionais tais como o crescimento e a dinamização da economia ou através do sistema democrático vigente. Eles defendem que é fundamental "compreender como a crise multiforme na qual vivemos, longe de ser um freio, se tornou um meio de governo". ${ }^{30}$ A crise seria até mesmo o paradigma da forma de governo atual. Nesta crise o Estado cumpre uma nova função, ele passa a ser visto ao mesmo tempo como o responsável e a válvula de escape de todas as crises sociais e sobretudo das crises financeiras. Responsável, em um primeiro momento, por acumular uma dívida pública e, em um segundo momento, uma válvula de escape por absorver continuamente as dívidas privadas. ${ }^{31}$ É o que os autores chamam de "milagre da dívida pública" que

permite a transferência de recursos dos mais pobres para os mais ricos graças às medidas de austeridade colocadas em prática pelos Estados. É a continuação lógica da política que consistiu em financiar os Estados por empréstimos junto aos mercados financeiros. Transferir financeiramente os custos da crise de acionários privados aos contribuintes, dito de outra forma passar de uma crise da dívida privada à uma crise das "dívidas soberanas", foi uma obra prima deste governo pela crise. ${ }^{32}$

Não são mais as populações, mas o Capital que passa a ser protegido pelo Estado. O que no fundo seria, se seguirmos o raciocínio do filósofo Anselm Jappe, a sua essência se revelando de forma mais explícita em uma época de crise. O autor não nos deixa esquecer que "o reforço do monopólio da violência pelo Estado e sua transferência aos particulares não estão em contradição: a violência é o núcleo do Estado, e sempre foi. Nesses tempos de crise, o Estado se transforma de novo no que foi historicamente em seus primórdios: um bando

27 DARDOT, Pierre; LAVAL, Christian. Ce cauchemar qui... Op. cit., p. 38-39.

${ }^{28}$ Ibidem, p. 32.

${ }^{29}$ Ibidem, p. 29.

30 Ibidem, p. 16.

${ }^{31} \mathrm{Em}$ uma leitura da crise que segue por uma direção semelhante, o sociólogo Wolfgang Streeck acrescenta a este esquema acima descrito por Dardot e Laval, que parte de um momento de dívida pública para outro de dívida privada, um terceiro momento que antecede aos dois precedentes: o da inflação. Desta forma, nos termos de Streeck, desde o estouro da crise nos anos 70, o capitalismo estaria de fato comprando tempo e esta compra se seguiu nestas três fases: inflação, dívida pública e dívida privada. A utopia (ou distopia sob outro ponto de vista) do ponto de vista sistêmico seria a despolitização completa da economia que permitiria um controle direto das nações pelo capital internacional ou, em outras palavras, um regime de austeridade total. Algo não muito distante da governabilidade neoliberal descrita por Dardot e Laval. Cf.: STREECK, Wolfgang. Buying time: the delayed crisis of democratic capitalism. London \& New York: Verso, 2014.

32 DARDOT, Pierre; LAVAL, Christian. Ce cauchemar qui... Op. cit., p. 35. 
armado". ${ }^{33}$ A crise passa a ser um mote para que todas as medidas vindas do Estado sejam revertidas para a classe que detém o capital e, desta maneira, tudo que antes parecia ser um obstáculo passa literalmente a ser uma oportunidade. Estas oportunidades agora são, no entanto, de qualidade diferente. Se antes estas poderiam ser vistas como oportunidades para se expandir a economia e medidas sociais viabilizadas pelo Estados, as novas oportunidades que surgem vão na direção contrária pois tendem simultaneamente a contrair a economia e acabar definitivamente com qualquer medida social veiculada pelo Estado. Esta governabilidade dominante, que é no fundo o que Dardot e Laval chamam por neoliberalismo, ${ }^{34}$ se radicalizou após a crise de 2008. Desde então o sistema não só não afundou como se tornou mais potente, "ele não faz apenas sobreviver, ele se reforçou se radicalizando". ${ }^{35}$ É esta a situação que Paulo Arantes tem chamado de "colapso administrado" que agora se generalizou e chegou no núcleo do sistema capitalista. ${ }^{36}$

Como uma forma de indiretamente reafirmar a sua opção pelo "comum", Dardot e Laval não poupam críticas ao papel desempenhado pelas esquerdas sociais-democratas tradicionais na implementação dessas políticas de governo neoliberal. Eles alegam não ser possível colocar a culpa, como normalmente alegado, em uma realidade que teria sido imposta de cima para baixo sobre as esquerdas no momento em que estas chegam ao poder. A situação teria sido exatamente a oposta, pois, segundo os autores, estas esquerdas teriam no fundo aderido formalmente ao programa e a princípios tradicionalmente ligados à direita, tais como a flexibilização do mercado de trabalho e a estabilidade monetária, "prisioneira desta lógica da liberdade de circulação de capitais e da competição, ela acabou por dar sempre razão às reivindicações do capital e não às do trabalho". ${ }^{37}$ Isto teria sido, por exemplo, claramente perceptível na França com François Mitterand e na Grécia Alexis Tsipras e o Syriza, mas não se reduziria nem a estes países nem a estes momentos. Esta adesão formal e convicta ao programa da direita explicaria segundo os autores o descrédito total e até mesmo o quase desaparecimento das esquerdas em diversos países europeus.

É exatamente deste problema que surge o subtítulo do livro de Dardot e Laval: o neoliberalismo desfaz a democracia. Para os autores a radicalização desta governabilidade neoliberal aliada à adesão formal daqueles que se propunham a enfrentá-la no âmbito formal cria uma situação em que o sistema democrático que foi construído no pós-guerra se torna mais e mais inoperante e tende a se tornar cada vez mais obsoleto. ${ }^{38} \mathrm{~A}$ redução do Estado ao aparato repressivo e a gestão de crise são as formas mais aparentes desse desmonte. Não foi apenas por acaso que Anselm Jappe observou que "a tendência ao Estado policial parece mais

\footnotetext{
33 JAPPE, Anselm. Violência, mas para quê? In: Crédito à morte: a decomposição do capitalismo e suas críticas. São Paulo: Hedra, 2013, p. 70.

${ }^{34}$ Cf.: DARDOT, Pierre, LAVAL, Christian. La nouvelle raison du monde: essai sur la société néoliberale. Paris: La Découverte/poche, 2010.

35 DARDOT, Pierre; LAVAL, Christian. Ce cauchemar qui... Op. cit., p. 25.

${ }^{36}$ ARANTES, Paulo, Depois de junho a paz vai ser total. In: O Novo Tempo do Mundo: e outros estudos sobre a era da emergência. São Paulo: Boitempo, 2014, p. 441.

37 DARDOT, Pierre; LAVAL, Christian. Ce cauchemar qui... Op. cit., p. 41.

38 É importante ressaltar que eles não discutem a fundo os eventuais opositores que tentam se colocar fora do quadro institucional.
} 
desenvolvida na França do que em qualquer outra "velha democracia". ${ }^{39}$ Este ponto, no entanto, merece um adendo. Se é verdade que não cabe aqui discutir em detalhes as condições históricas para que esta democracia fosse possível, não obstante, é necessário tê-las sempre em mente. Afinal, sem a Segunda Guerra Mundial e a Guerra Fria que se seguiu, esta última estando dividida em dois campos políticos antagonistas em disputa, esta democracia de bem-estar social não teria sido possível nem na Europa e nem nos Estados Unidos, ${ }^{40}$ e ainda muito menos os raros espasmos desta mesma democracia que ocorreram aqui e alí na periferia do sistema capitalista. Não é por acaso que ao final dessa Guerra Fria, mesmo nos países centrais, este sistema vem sendo cada vez mais esvaziado do seu conteúdo e se tornando uma democracia meramente formal. Um simples ritual onde se vota por um candidato que muito possivelmente não cumprirá o programa por ele proposto ${ }^{41}$ ou ainda, sabendo-se de antemão que o não cumprimento das promessas será o destino do seu voto, assume-se a abstenção e não se vai mais votar. ${ }^{42}$ Desta forma a democracia se torna efetivamente esvaziada, inclusive e sobretudo do demos. Ou ainda como dirá Anselm Jappe

A "democracia" é mais do que nunca puramente formal e se limita à escolhas periódicas entre os representantes das diferentes nuanças da mesma gestão (e até esse resto de escolha é viciado). Toda e qualquer oposição à política das instâncias eleitas que vai além de um abaixo-assinado ou de uma carta ao deputado local é por definição "antidemocrática". ${ }^{43}$

Desta maneira Jappe segue por uma direção oposta à de Myriam d'Allonnes quando aponta que as novas formas de mobilização saudadas mais acima pela autora, não passariam na realidade de mais uma expressão deste esvaziamento da democracia. Se seguirmos Jappe, ao contrário de serem uma renovação política, como pretende defender d'Allonnes, estas práticas seriam de fato mais um sintoma do agravamento da governabilidade neoliberal da qual nos falam Dardot e Laval. Os abaixo-assinados, os fóruns cidadãos ou as petições seriam no fundo manifestações desta formalidade esvaziada de conteúdo que vem se tornando a democracia liberal. Por outro lado, um dos limites da análise de Dardot e Laval talvez esteja exatamente em não explicitar de forma clara ao que esta democracia que o neoliberalismo está desfazendo estava de fato subsumida e que era condicionada àquela configuração mundial anterior. No limite, ficamos em dúvida se para os autores não seria apenas o neoliberalismo que seria de natureza antidemocrática e não o sistema capitalista como um todo. Se for este o caso, haveria nesta análise a possibilidade, mesmo que latente, de alguma volta a um

\footnotetext{
39 JAPPE, Anselm. Violência, mas para... Op. cit. , p. 70.

40 Cf.: MARCUSE, Herbert. L'homme unidimensionnel: essai sur l'idéologie de la société industrielle avancée. Paris: Les Éditions de Minuit, 1968. Nesta obra, entre outras coisas, Marcuse detalha o tipo de sociedade que foi construída nesta época e o guarda-chuva militar que era necessário para mantê-la funcionando.

${ }^{41}$ É neste ponto que reside uma das originalidades do atual presidente francês Emmanuel Macron, pois, ao menos até o presente momento, ele está efetivamente pondo em prática o programa para o qual foi eleito.

${ }^{42}$ Nas últimas eleições presidenciais francesas as abstenções foram, respectivamente, de $22,23 \%$ no primeiro turno e de $25,38 \%$ no segundo turno. Disponível em: <http://www.leparisien.fr/elections/presidentielle/presidentielle-I-abstention-en-hausse-par-rapport-au1er-tour-une-premiere-depuis-50-ans-05-05-2017-6919722.php>. Acesso em: 08 nov. 2017.

43 JAPPE, Anselm. Violência, mas para... Op. cit., p. 68.
} 
"capitalismo mais humano" ou o aperfeiçoamento da situação atual sem sair de fato dos limites do sistema. Essa ambiguidade talvez seja um dos limites da análise deles. ${ }^{44}$

No entanto, eles operam um outro gesto bastante interessante e produtivo na nomeação do que de fato seria a crise. Segundo Dardot e Laval, este processo contínuo de decomposição da democracia exercido pelo neoliberalismo desde pelo menos meados dos anos 70 deveria não mais ser entendido como uma "crise" no sentido clássico do termo, mas como uma guerra política. De certa forma, eles fazem um diagnóstico semelhante ao de Myriam Revault d'Allonnes porém ao invés de dizer que a crise seria na realidade uma metáfora para algo que não conseguiríamos plenamente conceitualizar, que é a tese defendida pela autora, eles afirmam que a crise seria na verdade o nome que estamos dando para uma guerra: "o termo "crise", empregado depois de trinta ou quarenta anos para designar um mecanismo objetivo independente da ação dos homens, mascara na realidade uma guerra política, de atores múltiplos, privados e públicos, nacionais e mundiais". ${ }^{45} \mathrm{O}$ regime de austeridade, ou seja, a guerra econômica que visa destruir e reestruturar a organização social, seria a face atual que esta guerra tem tomado. E um dos seus objetivos principais seria o de desativar qualquer dispositivo que poderia ser capaz de fazer face a esta lógica de guerra do sistema capitalista. Todavia, podemos imaginar que é bem provável que o próprio sistema não contasse com a adesão muitas vezes espontânea e quase que total de boa parte daqueles que em algum momento ao menos esboçaram ou ameaçaram fazer frente a essa lógica governamental de guerra social. Seguindo este fio, não teria sido por acaso que o "comum" não tomou rapidamente a forma que os autores imaginavam e apostaram que ele tomaria. A sua adoção, ou de qualquer outro princípio como um princípio organizacional, está de certa forma subsumida à uma arena de combate que é de antemão bastante assimétrica. Uma arena que no fundo seria uma guerra que não mostra explicitamente toda a sua face e conteúdo. Assim, se na atualidade "a política enquanto exercício do poder não é nada além da forma sob a qual a guerra de classes é incansavelmente conduzida pela oligarquia político-financeira", ${ }^{46}$ a retomada da iniciativa política se torna fundamental, clamam os autores.

\section{Crise e motim 47}

\footnotetext{
${ }^{44}$ Anselm Jappe tem insistido bastante em apontar esta dubiedade no conteúdo da crítica ao sistema capitalista é, segundo ele, possível de ser encontrada em diversos autores contemporâneos. Não estaria sempre claro se a crítica se dirige ao sistema capitalista como um todo ou apenas a uma das suas diversas faces possíveis. Ele observa, por exemplo, que "a nostalgia do capitalismo pretensamente "são" de ordem keynesiano-fordista é bastante repandida atualmente, sobretudo na França". In: La société autofage: capitalisme, démesure et autodestruction. Paris: La Découverte, 2017, p. 148. No entanto, vale aqui uma ressalva. É nesta obra específica, Ce cauchemar qui n'en finit pas, cuja forma pode ser vista como sendo a de um texto de intervenção política que contém em si um resumo das duas obras anteriores - La nouvelle raison du monde e Commun, ou seja, é um texto menos teórico que os antecessores - que essa ambiguidade de Dardot e Laval se encontra mais acentuada.

${ }^{45}$ DARDOT, Pierre; LAVAL, Christian. Ce cauchemar qui... Op. cit., p. 42.

${ }^{46}$ Idem.

${ }^{47}$ Escolhemos o termo motim como tradução para o termo riot, que é utilizado por Joshua Clover, por acharmos que ele representa melhor a ambiguidade e diversidade de forma com que o riot aparece no texto. Outras opções que nos foram sugeridas como: rebelião, insurreição ou tumulto nos pareceram ser
} 
A tese defendida pelo crítico literário Joshua Clover é que a crise do sistema capitalista que toma forma a partir dos anos 70 vem acompanhada, também, de uma mudança no paradigma da forma das lutas sociais: no lugar das greves, forma mais tradicional das lutas do período histórico anterior, teríamos agora os motins como a forma dominante. ${ }^{48}$ Vem daí a sua proposta de tentar elaborar uma teoria dos motins, pois sob seu ponto de vista "uma teoria do motim é uma teoria da crise". ${ }^{49}$ Esta teoria vem de certa forma do excesso, de uma experiência própria de alguns excessos e dentre esses o excesso de população é o que chama mais a atenção e o que vai ser central na argumentação de Clover. ${ }^{50}$ Excesso de população que parece de certa forma ser um crônico e se manifesta mais claramente no crescimento exponencial da presença do trabalho informal, inclusive nos países centrais do capitalismo. O próprio motim seria em si um excesso. No fundo a crise seria também a expressão de uma profunda reestruturação social que, como observa o autor, atinge profundamente a organização do trabalho criando uma contradição fundamental que é a de que o "capital talvez não precise destes trabalhadores, mas eles ainda precisam trabalhar". ${ }^{51}$ Desencontro esse que é no fundo a estrutura mesma destes motins que encarnam um deslocamento profundo que é a localidade e temporalidade das lutas.

Clover observa que a forma de luta em greve era prioritariamente ligada ao local de trabalho, não é a toa que o operário, sujeito político central deste período, era o trabalhador do mais emblemático destes locais: a indústria. Além disto, a indústria é o local por excelência da produção de capital. O chão da fábrica era desta maneira o lugar propício para a greve. Com o desemprego em massa e o excesso de população seria natural, sob os olhos do autor, que estas lutas sofressem uma transferência. Desta maneira a luta sairia do local de produção e passaria a acontecer prioritariamente nos locais de circulação do capital. Na nova era dos motins a praça e a rua são os locais privilegiados das lutas, o "motim deve em última instância ser entendido como uma luta de circulação". ${ }^{52}$ Esta ênfase na circulação também estaria diretamente relacionada à mudança de lógica de produção do fordismo para o toyotismo. Devido à crise o próprio capital se reorientou para a esfera da circulação, logo "inseridos no espaço de circulação, o motim se encontra onde o capital progressivamente transferiu os seus

menos propícias para caracterizar esta dubiedade do riot. Agradecemos a Germano Nogueira, Victor Marques e Rodrigo Nunes pelos generosos conselhos nem sempre seguidos e assumimos inteira responsabilidade pela escolha da tradução.

48 Joshua Clover faz uma periodização histórica em três eras, cada uma com predomínio de uma forma de luta: entre 1714 e algum momento entre 1790 e 1842 houve o primeiro predomínio da forma de riot (motim). Este segundo momento, inaugurado entre 1790 e 1842 tem o predomínio da forma de greve (strike) e se encerra entre maio de 1968 e a crise de 1973-74. A partir deste momento seriam novamente os riots que passaram a prevalecer como forma. O autor, podemos inferir, é consciente de que as formas se sobrepõem. Cf.: CLOVER, Joshua. Riot, Strike, Riot. The new era of uprising. Londres \& New York: Verso, 2016.

${ }^{49}$ Ibidem, p. 1.

${ }^{50} \mathrm{O}$ autor fala de excesso de informação, militarização, emoções e perigos. Poderíamos tomar a liberdade de acrescentar, entre outros excessos, o de tecnologia e o de velocidade.

${ }^{51}$ Ibidem, p. 26.

52 CLOVER, Joshua. Riot, Strike, Riot... Op. cit., p. 28. 
recursos" e assim "confronta o capital lá onde ele é mais vulnerável". ${ }^{53}$ Se as fábricas na sua maior parte estavam afastadas dos centros das cidades ou ainda aglomeradas em complexos industriais nas margens das metrópoles, os motins são essencialmente expressões de lutas urbanas. Elas têm como objetivo controlar a passagem por este espaço. Os motins ocorrem e vão ocorrer aonde as pessoas estão. Os "motins são obcecados com prédios, com praças e passagens, com aglomerações em praças e ruas", ${ }^{54}$ não é a toa que a barricada foi um dos grandes símbolos da primeira era dos motins. ${ }^{55}$ Clover ainda aponta que "a espacialidade prática dos motins corresponde a uma distinção teórica. A lógica abstrata da produção é temporal, a lógica abstrata da circulação é espacial". ${ }^{56}$ Portanto a greve é uma luta ligada essencialmente ao tempo enquanto os motins ao espaço. Neste ponto não deixa de ser interessante seguir a observação do filósofo Jean-Paul Dollé, quando ele afirma que não foi por acaso que a crise de 2008 explodiu a partir de uma crise de subprimes ligadas ao financiamento de casas nos Estados-Unidos. Esta é uma crise que explode a partir da crise urbana. Uma crise que como ele observa sofre de "indeterminação espacial"57 e que encarna o paradoxo de exatamente na era da velocidade, mobilidade e comunicação ter a casa, um bem fixo e habitável, como estopim. ${ }^{58}$

Por outro lado, Clover observa que os críticos da forma motim geralmente se detêm e concentram as suas críticas em um ponto chave que é o da falta de programa ou de afirmação desta forma política. Ele diz que "o motim não almeja preservar nada, não afirma nada além de um antagonismo compartilhado, de uma miséria compartilhada, de uma negação compartilhada. Lhes falta um programa", ${ }^{59}$ e ele acrescenta ainda que "a luta na circulação não requer que os seus participantes sejam trabalhadores...qualquer um pode liberar um mercado, fechar uma estrada, fechar um porto... os participantes não estão unificados pela posse de empregos mas pela sua mais geral despossessão". ${ }^{60}$ De certa forma, as observações de Clover parecem convergir com uma outra de Anselm Jappe quando este último observa que na atualidade "o que o Estado teme são movimentos sem chefes e que fogem do enquadramento", ${ }^{61}$ ou seja, talvez seja exatamente este silêncio e a negação de modos mais tradicionais de atuação política que dificulta o reconhecimento por parte do Estado. Talvez o que este último mais tema seja a falta de programa e de afirmação.

\footnotetext{
53 Ibidem, p. 30.

54 Ibidem, p. 138.

55 Cf.: HAZAN, Eric. La Barricade: histoire d'un objet révolutionnaire. Paris: Autrement, 2013.

${ }^{56}$ CLOVER, Joshua. Riot, Strike, Riot... Op. cit., p. 138.

57 DOLLÉ, Jean-Paul. L'inhabitable capital. Crise mondiale et expropriation. Paris: Lignes, 2010, p. 11.

58 É interessante termos em mente que Jean-Paul Dollé também afirma que os Estados-Unidos são no fundo o país do espaço (Ibidem, p. 31-40) e que boa parte do material teórico e histórico que Joshua Clover toma como objeto e ponto de partida para elaborar a sua teoria das insurreições foram acontecimentos que ocorreram em centros urbanos dos Estados-Unidos como: Fergunson (2014), Oakland (2011), Baltimore (2015) entre outros (é verdade também que ele não fica restrito aos EUA e passa por países como França e Inglaterra, mas as suas análises se concentram nos casos americanos). Ele também deixa claro que está elaborando uma teoria relacionada e a partir de países ocidentais e centrais e que possivelmente para pensar a China ou Índia outra teoria seria necessária. Sugerir que esta teoria pode ser interessante para se pensar o Brasil é um dos objetivos que têm este artigo.

59 CLOVER, Joshua. Riot, Strike, Riot... Op. cit., p. 150.

60 Ibidem, p. 151.

61 JAPPE, Anselm. Violência, mas para... Op. cit., p. 79.
} 
Outro aspecto central que vem à tona logo que um motim toma forma, ou em qualquer discussão em torno de qualquer forma de ação política que se situe no limiar da legalidade, é a questão da violência. Clover argumenta que denunciar e sobretudo rejeitar estas práticas por serem violentas implica um certo a priori em relação ao direito à propriedade privada. No fundo esta insistência por parte daqueles que denunciam os motins por serem geralmente excessivamente violentos seria uma maneira de acobertar que no fundo elas não deixam de ser manifestações reativas a uma outra violência. Se nos colocarmos de acordo com Pierre Dardot e Christian Laval quando estes dizem que no fundo o que estamos chamando de crise é na realidade uma guerra política, seria no mínimo esperado que qualquer tipo de reação a esta crise-guerra pudesse alcançar proporções violentas. Um outro aspecto fundamental é que esta violência é cada vez mais dirigida contra o Estado. No período anterior, observa Clover, "o estado estava longe e a economia próxima"62 e desta forma a luta tinha como objetivo prioritário parar a produção. Ou seja, o sujeito antagonista era, por assim dizer, ou o patrão ou aquele que estivesse alí lhe representando na fábrica. Na era atual teríamos a situação contrária, "o estado está próximo e a economia longe". ${ }^{63}$ O que inevitavelmente, se continuarmos seguindo o autor e tivermos em mente a acentuação do caráter policial do estado como foi apontado mais acima por Anselm Jappe, resultará em um excesso de violência vindo de ambos os lados. É face a um Estado cada vez mais armado e repressivo que os motins têm se deparado. Se por um lado não nos cabe julgar se estes excessos de violência são justificáveis ou não; por outro lado, não podemos de forma alguma cair na armadilha de condenar de antemão os motins. Anselm Jappe, por exemplo, ao mesmo tempo em que observa que "vai ser muito difícil que os atos de contestação, que não deixarão de aumentar nos próximos anos, respeitem os parâmetros da 'legalidade' concebidos precisamente no objetivo de condená-los à ineficácia", ${ }^{64}$ crê que atos de sabotagens poderiam ser politicamente mais eficientes que os motins. Embora as sabotagens também sejam ilegais, o autor aponta que no fundo a violência seria um terreno que o Estado domina e para o qual está mais preparado e que desta forma as sabotagens poderiam ter um maior êxito. Paulo Arantes, por outro lado, em uma crítica direcionada ao texto de Anselm Jappe, aponta que no fundo seria difícil imaginar que exista alguém que se encontre nestas situações de "humilhação social" extrema provocada pela situação de crise total do presente, que consiga evitar totalmente o uso da violência, e ele acrescenta que "ao longo de uma crise que já dura trinta anos, muitas coisas se degradaram, e desse apodrecimento não escapam também a violência e ilegalidade". ${ }^{65} \mathrm{E}$ se, em uma época de excessos, a política passou a ser a forma com que a guerra social passou a ser conduzida, como foi observado mais acima por Dardot e Laval, é quase inevitável que a violência reativa não afirmativa e desvinculada de um programa claro também apareça como excessiva.

${ }^{62}$ CLOVER, Joshua. Riot, Strike, Riot... Op. cit., p. 29.

63 Idem.

64 JAPPE, Anselm. Violência, mas para... Op. cit., p. 75.

${ }^{65}$ ARANTES, Paulo. Depois de junho... Op. cit., p. 443-444. 
Entretanto, no final da sua obra, Clover admite que o motim na sua forma atual predominante apresenta um certo limite pois, no fundo, ele seria muito mais um ato simbólico do que concreto. A interrupção da circulação de capital que ele exerce seria mais performativa do que realmente efetiva. Uma ação que abre um campo de possibilidades, mas que devido à sua natureza não o concretiza plenamente. O autor tenta, por esta razão, derivar do motim um esboço de uma proposição e possibilidade, sob seu ponto de vista, mais concreta, que não mais seria o "comum", como é proposto por Dardot e Laval, mas uma outra palavra de mesma etimologia: a comuna.

\section{Comuna: impasse ou saída da crise?}

Para Joshua Clover uma eventual aparição e proliferações de comunas em um hipotético futuro poderia ser diretamente deduzida da situação atual: "se a praça e a rua foram os dois lugares da insurreição, ambos abrem espaço para a comuna", ${ }^{66}$ afirma o autor. Embora talvez devêssemos nuançar esta afirmação e tomá-la mais como uma aposta do que como propriamente uma dedução, esta dedução ou aposta feita pelo autor tem como base alguns preceitos fundamentais. Segundo ele, a forma da comuna é capaz de criar um chão comum para que antinomias históricas sejam efetivamente suportadas - como por exemplo aquela que separa socialistas, comunistas e anarquistas - e possibilitar com que práticas que já estejam de certa forma latentes na situação imediatamente precedente tomem finalmente forma e sejam efetivamente experimentadas, como por exemplo a aparição política concreta de mulheres, crianças, camponeses, idosos, desempregados por ocasião da Comuna de Paris em 1871, como apontado pela historiadora Kristin Ross e por sua vez referenciada por Clover. Desta maneira "com as transformações do presente, a forma da comuna é impensável sem a modulação da classe trabalhadora tradicional para um proletariado expandido", 67 os trabalhadores estão, mas não mais apenas como trabalhadores. Aqueles não identificados como trabalhadores podem aparecer plenamente através dessa expansão do proletariado para além dessa identidade. A sua aposta consiste em afirmar que serão em comunas futuras que novos sujeitos políticos poderão tomar forma.

A "comuna vai além da produção e consumo capitalista", ela ao mesmo tempo "é uma abertura histórica, e também um encerramento". ${ }^{68}$ Indo nesta direção o acento dado por Kristin Ross ao que foi imaginado e colocado em prática durante a Comuna de Paris parece ser uma abordagem promissora. Além do mais, sob o olhar da autora, o mundo presente se pareceria muito mais com o mundo de onde a comuna emergiu do que 0 mundo imediatamente anterior, o mundo da era de lutas em forma de greves. Embora exista uma discordância entre Ross e Clover - para este a época da aparição da Comuna de Paris já era a

${ }^{66}$ CLOVER, Joshua. Riot, Strike, Riot... Op. cit., p. 187.

67 Ibidem, p. 189.

${ }^{68}$ CLOVER, Joshua. Riot, Strike, Riot... Op. cit., p. 190. 
época da predominância da forma das greves -, ambos os autores fazem a aposta de uma possível latência da forma da comuna no mundo presente. Ross observa ainda que a Comuna de Paris, estando não obstante territorialmente aquém, apontou para além do estado e da nação francesa. Ela sugere que "a imaginação da Comuna operou na escala preferencial da unidade de autonomia local com um horizonte internacional" ou ainda que ela "foi um trabalho de invenção política, improvisado no local ou recortado de cenários e frases passadas, reconfigurado como necessário, e alimentado por desejos despertados em reuniões no final do Império". 69 Trazendo à tona e dando vida a pensamentos e desejos experimentados e imaginados anteriormente de maneira coletiva, a comuna foi, de certa forma, a concretização de uma tentativa de ultrapassar o limiar do que lá estava instituído. Embora estivesse territorialmente aquém, ela estava além do que havia de politicamente instituído na França. $O$ geógrafo David Harvey sugere algo parecido para o presente quando aponta que diversas inovações já existentes poderiam ser reunidas no intuito de se construir uma alternativa ao neoliberalismo, mas que isso passa necessariamente pela "criação de espaços urbanos comuns". $^{70}$ Se por um lado ele não parece ter soluções prévias para esse impasse, Harvey sugere que é fundamental imaginarmos esse outro mundo no qual gostaríamos de viver e construir - um gesto muito próximo ao exercício imaginativo dos communards nos meses anteriores à comuna, como apontado por Ross.

É nesta direção que, criticando a leitura do filósofo Alain Badiou - que analisa a Comuna de Paris através da sua própria terminologia filosófica como um "evento" ou "acontecimento" político $^{71}$-, Joshua Clover defende que "a comuna emerge não como um 'acontecimento' mas como uma tática de reprodução social"; e, que "a comuna é uma tática que também é forma de vida". ${ }^{72}$ Kristin Ross, por sua vez, considera que, quando inicia a sua análise da Comuna no dia 18 de março, Badiou, seguindo a historiografia dominante, coloca em segundo plano tudo o que foi imaginado nos meses que antecederam a sua aparição efetiva e esse gesto termina por sujeitá-la a um "paradigma pedagógico" de onde se deve tirar "lições" para ações futuras. A historiadora afirma que "adotando esta postura, perde-se todo o senso da dimensão experimental da arte e da política" que foi a Comuna de Paris. ${ }^{73}$ Segundo a autora a Comuna não foi "apenas" um acontecimento, ela vai além dela mesma, e Badiou não teria levado isso completamente em conta. No entanto, embora as críticas de Clover e Ross nos pareçam justas, podemos nos colocar de acordo com Badiou quando este afirma que um dos maiores feitos da comuna foi o de "fazer aparecer no mundo o que não existia nele" criando desta maneira o sítio, no termo próprio a Badiou, necessário para que a tática e o imaginário ganhassem forma

\footnotetext{
${ }^{69}$ ROSS, Kristin. Communal luxury. The political imaginary of the Pariis Commune. London \& New York: Verso, 2015, p. 5, 11.

70 HARVEY, David. A liberdade da cidade. In: Cidades Rebeldes: Passe livre e manifestações que tomaram as ruas do Brasil. São Paulo: Boitempo, 2013, p. 33.

${ }^{71}$ BADIOU, Alain. A Comuna de Paris: uma declaração política sobre a política. In: A Hipótese Comunista. São Paulo: Boitempo, 2012, p. 124-126.

72 CLOVER, Joshua. Riot, Strike, Riot... Op. cit., p. 191.

73 NEVEUX, Olivier; ROSS, Kristin. L'événement en histoire: la Commune, mai 68. Actuel Marx: psychanalyse l'autre matérialisme, Paris, v. 1, n. 59, 2016, p. 204-205.
} 
concreta. ${ }^{74}$ Além disto, ao contrário de Badiou, que parece negligenciar ou colocar este aspecto em segundo plano, Ross e Clover insistem, nas suas respectivas análises, que a Comuna de Paris foi também uma resposta popular e política para a crise que a guerra contra a Prússia havia agravado na França. Não havia uma necessidade histórica prévia, mas foi a crise que abriu espaço para que esta forma política, que foi a comuna, emergisse daquele limiar onde convergiam abertura e encerramento histórico. E aquilo não era de forma alguma necessário e nem muito menos determinado pois são raras as outras ocasiões de crise em que algo similar surgiu. As crises são constantes, mas nem sempre algo emerge delas, nada está assegurado. No entanto, naquele momento limiar aconteceu. É por esta razão que Clover afirma que "a comuna não é nada mais do que o nome da tentativa para superar este limite". ${ }^{75} \mathrm{E}$ a superação deste limite é algo que aponta para muito além de uma brecha ou de um novo ponto de partida, como poderia afirmar D'Allones, pois se supõe que se possa instaurar algo de politicamente novo, que não será um mero recomeço, mas que faria aparecer o que ainda não existia e que estaria, de certa forma latente na imaginação e em certas práticas atuais. Clover aposta que

as comunas que virão vão se desenvolver onde ambas as lutas de produção e circulação tiverem se esgotado. É provável que as comunas que virão emerjam primeiramente não em cidade muradas ou em comunidades de retiro, mas em cidades abertas onde aqueles excluídos da economia formal e deixados à deriva em circulação agora percebam o fracasso do mercado em provir as suas necessidades. ${ }^{76}$

Com isso em mente, não deixa de ser interessante remarcar que, ainda na introdução da obra Commun, Pierre Dardot e Christian Laval façam a seguinte constatação:

se "Comuna" é o nome do autogoverno político local e "comuns" o nome dos objetos de natureza bastante diversa operados pela atividade coletiva de indivíduos, "comum" é propriamente o nome do princípio que anima esta atividade e que preside ao mesmo tempo a construção desta forma de autogoverno. ${ }^{77}$

Se nos colocarmos de acordo com Clover e Ross, talvez o que não tenha ainda surgido neste limiar de crise permanente no qual estaríamos inseridos são exatamente as comunas, ou seja, os locais de autogoverno político onde o "comum" - que talvez possa ser lido como algo próximo àquilo que Ross aponta como tendo sido imaginado nos meses que antecederam a Comuna de Paris - possa efetivamente tomar forma enquanto princípio.

Ao final, não deixa de ser curioso lembrarmos que em uma aula em praça pública ocorrida no auge das Jornadas de Junho de 2013 na cidade de São Paulo, jornadas que no fundo ninguém esperava e que de certa forma fizeram emergir e reconfiguraram definitivamente a crise na qual o Brasil se encontra atualmente, Paulo Arantes - que em

\footnotetext{
74 BADIOU, Alain. A Comuna de Paris... Op. cit., p. 124

75 CLOVER, Joshua. Riot, Strike, Riot... Op. cit., p. 192.

76 Ibidem, p. 191.

77 DARTOT, Pierre; LAVAL, Christian. Commun... Op. cit., p. 19-20.
} 
seguida qualificou-as de "utopia real"78 - tenha, em um devaneio, imaginado a possibilidade de uma proliferação de comunas Brasil afora:

Bem, vou falar sobre o meu devaneio - de gabinete, vale dizer. Imaginem uma cidade de 50 mil habitantes, uma cidade pequena. 30 mil saem às ruas, entram na prefeitura e tiram de lá o prefeito e os vereadores a pontapés. Começam a pôr ordem na casa: poder popular. Ou seja, outra reformulação de organização da vida. Se em 15 dias você tem 5 comunas, dali mais alguns já são 100: aí começa a ter uma outra conversa política, poder popular urbano. Isso é um devaneio, obviamente. ${ }^{79}$

Frederico Lyra de Carvalho: Doutorando em Filosofia da arte pela Université Lille 3 Sciences Humaines et Sociales. Possui mestrado em Estética Musical pela Université Paris Sorbonne e Licenciatura em Música pela Universidade Federal de Pernambuco (UFPE). Contribui para os sites LavraPalavra e Urucum, além de ser membro do CEII e do Autre Brésils.

78 ARANTES, Paulo. Depois de junho... Op. cit., p. 413.

79 ARANTES, Paulo. Tarifa zero e mobilização popular. Blog da Boitempo. (site). Disponível em <https://blogdaboitempo.com.br/2013/07/03/tarifa-zero-e-mobilizacao-popular/>. Acesso em: 05 nov. 2017. 